\title{
REtrospective Multicenter INdian Study of Derivo Embolization Device (REMIND): Periprocedural Safety
}

\author{
Niranjan Prakash Mahajan, DNB/DM, FNB ${ }^{1}$, Mudasir Mushtaq, DM, FINR ${ }^{1}$, Amit Bhatti, DNB/DM, FINR ${ }^{1}$ \\ Sukalyan Purkayastha, DNB/DM, CCST ${ }^{2}$, Nitin Dange, MCh, OBNI, FFHU ${ }^{3}$, Mathew Cherian, MD, PDCC ${ }^{4}$, \\ Vipul Gupta, MD ${ }^{5}$, Vikram Huded, DM, FINR ${ }^{1}$ \\ ${ }^{1}$ Division of Interventional Neurology, Department of Neurology, Mazumdar Shaw Medical Centre, Narayana Health City, Bangalore, India \\ ${ }^{2}$ Department of Interventional Neuroradiology, Institute of Neurosciences, Kolkata, India \\ ${ }^{3}$ Department of Neurosurgery, King Edward Memorial Hospital and Seth G.S. Medical College, Mumbai, India \\ ${ }^{4}$ Department of Diagnostic and Interventional Radiology, Kovai Medical Centre and Hospital, Coimbatore, India \\ ${ }^{5}$ Department of Neurointerventional Surgery, Artemis Hospital, Gurugram, India
}

Purpose: The treatment of aneurysms with characteristics such as complex morphology, fusiform, blister-like, wide neck, or large size has been revolutionized with the introduction of flow diverters. Though flow diverters have several advantages over coiling, they also have certain important disadvantages such as the lack of immediate protection against rupture, the risk of ischemic stroke, the need for antiplatelet therapy, and long latency for complete effect. The Derivo Embolization Device (DED) is a second-generation self-expanding device that is claimed to be less thrombogenic than conventional devices. We retrospectively evaluated the periprocedural safety and risks associated with the DED across 5 centers in India.

Materials and Methods: This is a multicentric, retrospective, observational study of DED, conducted at 5 high volume endovascular therapy centers in India from May 2018 to June 2020. Periprocedural demographic, clinical, and angiographic data were collected from a retrospective review of patient charts.

Results: A total of 96 patients, including 56 (58.3\%) females, aged between 16-80 years (60 \pm 12.7 years) harboring 106 aneurysms were studied. Seven (7.3\%) were noted to harbor multiple aneurysms: 6 had 3 aneurysms each, while 1 patient had 5 aneurysms. The following aneurysm characteristics were noted: average size, $9.8 \pm 8.2 \mathrm{~mm}$; average neck size, $6.9 \pm 8.5 \mathrm{~mm}$; wide-necked (>4 mm), 63 (59.4\%); giant (>25 mm), 8 (7.5\%); and anterior circulation location, 98 (92.5\%). Eighteen (17\%) of these were ruptured. Additional balloon angioplasty was performed in 5 (5.2\%) patients. Intraprocedural problems were encountered in 3 (3.1\%), of which only 1 had clinical implications, the device fish-mouthing with stent thrombosis resulting in a malignant middle cerebral artery territory infarction. The modified Rankin scale at 3 months was worse in 1 patient.

Conclusion: DED is a newer generation flow diverter stent with a low periprocedural complication rate.

Key Words: Aneurysm; Embolism; Hemorrhage; Stents; Thrombosis

\section{Correspondence to: Vikram Huded, DM, FINR \\ Division of Interventional Neurology, Department of Neurology, Mazum- dar Shaw Medical Centre, Narayana Health City, 258/A, Bommasandra Industrial Area, Anekal Taluk, Hosur Road, Bangalore, Karnataka 560099, India \\ Tel: $+91-9900002101$ \\ Fax: $+91-8027832648$ \\ E-mail:drvikramhuded@gmail.com}

Received: May 11, 2021

Revised: August 2, 2021

Accepted: August 4, 2021

Copyright $\odot 2021$ Korean Society of Interventional Neuroradiology This is an Open Access article distributed under the terms of the Creative Commons Attribution Non-Commercial License (http://creativecommons.org/licenses/by-nc/4.0) which permits unrestricted non-commercial use, distribution, and reproduction in any medium, provided the original work is properly cited. 


\section{INTRODUCTION}

Endovascular therapy with coiling has been shown to be a feasible and safe procedure for ruptured intracranial aneurysms and superior to clipping in the International Subarachnoid Aneurysm Trial.' However, soon it was realized that the recurrence rates with this modality of treatment were quite high. ${ }^{2}$ Further, this modality was not found suitable for all types of aneurysms, and some of the procedures required adjunctive use of balloons or stents. A new era, with a different concept of reconstructing the vessel lumen, emerged with the first generation of flow diverter devices. The Pipeline embolization device was the first in the series, and the Buenos Aires experience was the primal breakthrough. ${ }^{3}$ The pipeline embolization device for the intracranial treatment of aneurysms trial and the pipeline for uncoilable or failed aneurysms: results from a multicenter clinical trials further strengthened the evidence for its use especially in unruptured aneurysms that are difficult to coil. ${ }^{4,5}$ Flow diverter devices thus expanded the interventionists' armamentarium and were found to be a safe and effective treatment; unlike coiling, the occlusion rates were better the longer the follow-up., ${ }^{6,7}$ Though they are especially useful for unruptured aneurysms, they may also be of use for some ruptured subtypes, like blister-like aneurysms, in which they may be the mainstay therapy. ${ }^{8}$ The treatment of aneurysms with characteristics such as complex morphology, fusiform, blister-like, wide neck, or large size has been revolutionized with the introduction of flow diverter stents. The Pipeline Embolization Device was the first in the series. ${ }^{9}$ Since then, newer devices with further refinements have emerged. Though these devices have several advantages over coiling, they have certain important disadvantages like the lack of immediate protection against rupture, the risk of ischemic stroke, the need for antiplatelet therapy, and long latency for complete effect. ${ }^{10}$ As flow diverter devices gained popularity, studies brought out important risks associated with these devices. Thromboembolic events, intraparenchymal hemorrhage, and delayed aneurysm rupture are notable problems encountered in practice. ${ }^{6}$ In-stent thrombosis has been noted in around $5 \%$ of individuals in different studies. ${ }^{6,11-13}$ Intraparenchymal hemorrhage and delayed aneurysm rupture have been noted to occur in around $3 \%$ of individuals. ${ }^{14}$

As the devices have evolved over the years and with the increasing experience with this technology, year after year, the complication rates have fallen. Improved radio-opacity, the ability to resheath partially deployed devices and reduced thrombogenicity are a few of the advanced features with the newer devices, aiding easier and more accurate device deployment with reduced periprocedural complication

Table 1. Characteristics of some of the commonly used flow diverter devices

\begin{tabular}{|c|c|c|c|c|c|}
\hline Variable & Derivo & Pipeline shield & FRED & Surpass & Silk \\
\hline No. of wires & 48 wires & 48 wires & Overlap stent design & 64 Wires & 48 Wires \\
\hline Wire construction & $\begin{array}{l}48 \text { Hybrid nitinol } \\
\text { (DFT) wire }\end{array}$ & $\begin{array}{l}12 \text { Platinum, } 36 \text { cobalt } \\
\text { chromium wires }\end{array}$ & $\begin{array}{l}2 \text { Platinum, } \\
46 \text { nitinol wires }\end{array}$ & $\begin{array}{l}12 \text { Platinum, } 52 \text { cobalt } \\
\text { chromium wires }\end{array}$ & $\begin{array}{l}2 \text { Platinum, } 46 \\
\text { nitinol wires }\end{array}$ \\
\hline Surface finish & BlueXide & $\begin{array}{l}\text { Phosphoryl- } \\
\text { choline }\end{array}$ & NA & NA & NA \\
\hline Distal/proximal marker & $\begin{array}{l}3 \text { Markers at both } \\
\text { ends }\end{array}$ & NA & $\begin{array}{l}4 \text { Markers at both } \\
\text { ends }\end{array}$ & NA & NA \\
\hline Diameter & $2.5 \mathrm{~mm}$ to $6 \mathrm{~mm}$ & $2.5 \mathrm{~mm}$ to $5 \mathrm{~mm}$ & $2.5 \mathrm{~mm}$ to $5 \mathrm{~mm}$ & $2.5 \mathrm{~mm}$ to $5 \mathrm{~mm}$ & $2.25 \mathrm{~mm}$ to $5 \mathrm{~mm}$ \\
\hline Length & $15 \mathrm{~mm}$ to $50 \mathrm{~mm}$ & $12 \mathrm{~mm}$ to $35 \mathrm{~mm}$ & $12 \mathrm{~mm}$ to $48 \mathrm{~mm}$ & $15 \mathrm{~mm}$ to $40 \mathrm{~mm}$ & $10 \mathrm{~mm}$ to $35 \mathrm{~mm}$ \\
\hline Working length & End to end & End to end & $\begin{array}{c}\text { Both ends } 2 / 5 \mathrm{~mm} \\
\text { non-FD ends }\end{array}$ & End to end & End to end \\
\hline Distal wire end & Closed & Open & Open & Open & Open \\
\hline Catheter compatibility & $\begin{array}{l}0.021 \text { inch/ } \\
0.027 \text { inch }\end{array}$ & 0.027 inch & $\begin{array}{l}0.021 \text { inch/ } \\
0.027 \text { inch }\end{array}$ & 0.027 inch & $\begin{array}{l}0.025 \text { inch/ } \\
0.029 \text { inch }\end{array}$ \\
\hline FDA approval & Not approved & Approved & Approved & Approved & Not approved \\
\hline
\end{tabular}

Device specifications collected from the respective manufacturers.

FDA, US Food and Drug Administration; DFT, drawn filled tubes; FD, flow diverter; FRED, flow-redirection endoluminal device; NA, not applicable. 
rates. ${ }^{7,12,15}$ The Derivo Embolization Device (DED) (Acandis, Pforzheim, Germany) belongs to the newer generation of devices and is claimed to be superior to the older devices. The DED is a self-expanding device made up of Nitinol, and it is claimed to be less thrombogenic than other devices owing to its oxide and oxynitride coating. It has a porosity of $60-65 \%$ and surface coverage of 33-39\%, and the cross-sectional diameter of the wires is 0.003 to 0.009 inches. Its platinum core makes the device radio-opaque with better fluoroscopic visualization, and additional radiopaque markers at each of the 3 flared ends enhance it. Also, the device can be recaptured and repositioned before full deployment. ${ }^{6,8}$ Preliminary studies carried out in animal models show it to be less thrombogenic compared to the first-generation devices. ${ }^{16}$ However, experience with the newer devices is still evolving. ${ }^{17}$ Features and designs of some of the commonly used flow diverter stents are detailed in Table 1.

Experience with the use of this device, especially in the Indian context, is still in the preliminary stages. Nevertheless, it is becoming more and more popular across the country, as is seen with its use in the current study across 5 independent centers. We aimed to evaluate the periprocedural safety and risks for the DED in a retrospective manner.

\section{MATERIALS AND METHODS}

This is a multicenter, retrospective, observational study conducted at 5 high-volume endovascular therapy centers in India. Patients undergoing treatment with DED over a period of around 2 years (from May 2018 to June 2020) were studied. Demographic and clinical data were collected from patient chart reviews. Data about aneurysms and the parent vessels were obtained from the pre-procedure 4-vessel digital subtraction angiograms. Neurologic complications during and after the procedure were noted until discharge. The modified Rankin Scale (mRS) at 3 months was noted as an outcome measure.

\section{Inclusion Criteria}

Patients diagnosed with 1 or more aneurysms of the cerebral vessels who had undergone flow diverter stenting with the DED between 1st May 2018 to 30th June 2020 were included.

\section{Exclusion Criteria}

1. Aneurysms treated with any other methods (such as flow diverters other than DED, coiling, or intrasaccular devices). 2. Patients with incomplete clinical and angiographic data.

\section{Procedure}

All interventionists carrying out the procedures had at least 10 years of experience in endovascular surgery. All the procedures were carried out under general anesthesia with an $8 \mathrm{~F}$ and a $6 \mathrm{~F}$ short arterial sheath for anterior and posterior circulation aneurysms, respectively. Heparin was administered as a bolus of 5,000 IU through a short arterial sheath at the beginning of each procedure and repeated in aliquots of 1,000 IU/hour IV until the end of the procedure. The embolization device was delivered through a 0.027 inch microcatheter, and the deployment was considered successful if the device covered the aneurysm neck completely and the post-procedure angiogram showed good apposition of the stent to the vessel wall. The use of adjunctive measures like balloon angioplasty and coiling was left to the discretion of the interventionist. All patients were treated with dual anti-platelets before the procedure and after the procedure (Aspirin and Ticagrelor/Clopidogrel) for at least 3-6 months and a single antiplatelet agent thereafter.

\section{Statistical Analysis}

Frequencies and percentages are presented for categorical variables while means and standard deviations are stated for continuous variables. Statistical analysis was done using Microsoft Excel (version 2016; Microsoft, Redmond, WA, USA).

\section{RESULTS}

A total of 96 patients aged between $16-80$ years $(60 \pm 12.7$ years) were studied. Fifty-six (58.3\%) of these were females. Seven individuals (7.3\%) were diagnosed to harbor multiple aneurysms: 6 individuals had 2 aneurysms each, while 1 individual had 5 aneurysms. Thus, a total of 106 aneurysms were identified in the study cohort. Ninety-eight (92.5\%) of the 106 aneurysms were located in the anterior circulation, whereas 8 (7.5\%) were in the posterior circulation. Eighty-eight (83\%) of the 106 were unruptured and 18 (17\%) were ruptured. The average size of the aneurysms was $9.8 \pm 8.2 \mathrm{~mm}$ (range 1 to $35 \mathrm{~mm}$ ) with an average neck size of $6.9 \pm 8.5 \mathrm{~mm}$. Sixty-three (59.4\%) of these had necks wider than $4 \mathrm{~mm}$. Eight (7.5\%) of the 106 were $>25 \mathrm{~mm}$ in size. Saccular aneurysms constituted the most common sub-type $(84,79.2 \%)$, and the internal 
carotid artery was the most common vessel involved ( 75 , 70.7\%) (Table 2).

Additional balloon-angioplasty was performed in 5 (5.2\%) patients, and aneurysm coiling was performed in 12 (12.5\%). Eighteen (17\%) of these had ruptured aneurysms, including 6 (6.2\%) that had been treated earlier with either clipping or coiling and were detected to have regrowth or a persistent residual neck, and hence received flow diverter stenting. The remaining 12 included 6 each of the dissecting type and the blister type. Fifteen of these had ruptured in less than 10 days of presentation (mean 3.9 days, range 2 to 9 days), while 3 had ruptured more than a month prior. Intraprocedural complications occurred in 3 individuals (3.1\%), and 1 out of 3 (1\%) was clinically significant. Device fish-mouthing occurred in a middle-aged patient who had a ruptured dissecting middle cerebral artery aneurysm with subarachnoid hemorrhage. Stent thrombosis followed by a malignant middle cerebral

\section{Table 2. Aneurysm characteristics and outcome}

\begin{tabular}{|c|c|c|}
\hline Parameter & & Frequency $(n=106)$ \\
\hline \multirow{2}{*}{$\begin{array}{l}\text { Presenting } \\
\text { pattern }\end{array}$} & Ruptured & $18(18.7)$ \\
\hline & Unruptured & 78 (81.3) \\
\hline \multirow[t]{9}{*}{ Location } & Internal carotid artery & $75(70.7)$ \\
\hline & Middle cerebral artery & $9(8.5)$ \\
\hline & $\begin{array}{l}\text { Anterior communicating } \\
\text { artery }\end{array}$ & $6(5.7)$ \\
\hline & Anterior cerebral artery & $5(4.7)$ \\
\hline & Basilar artery & $4(3.8)$ \\
\hline & Vertebral artery & $3(2.8)$ \\
\hline & $\begin{array}{l}\text { Posterior communicating } \\
\text { artery }\end{array}$ & $2(1.9)$ \\
\hline & Anterior choroidal artery & $1(0.9)$ \\
\hline & Posterior cerebral artery & $1(0.9)$ \\
\hline \multirow[t]{4}{*}{ Type } & Saccular & $84(79.2)$ \\
\hline & Fusiform & $10(9.4)$ \\
\hline & Blister & $6(5.7)$ \\
\hline & Dissecting & $6(5.7)$ \\
\hline Size (mm) & & $9.8 \pm 8.2(1-35)$ \\
\hline \multirow{2}{*}{$\begin{array}{l}\mathrm{mRS} \text { at } \\
\text { presentation }\end{array}$} & 0 & $78(81.3)$ \\
\hline & 1 & $18(18.7)$ \\
\hline \multirow{2}{*}{$\begin{array}{l}\text { mRS at } \\
3 \text { months }\end{array}$} & 0 & $95(99)$ \\
\hline & 4 & $1(1)$ \\
\hline
\end{tabular}

Values are presented as number (\%) or mean \pm standard deviation (range).

mRS, modified Rankin Scale. artery territory infarction occurred in him despite the use of Tirofiban infusion and a combination of Aspirin and Ticagrelor. Coiling also had been attempted with this patient. In another patient with an A1 segment of anterior cerebral artery dissecting aneurysm, the device landed at the terminal internal carotid artery (at the proximal M1 segment) resulting in flow-limitation in the middle cerebral artery; hence, a balloon was taken into the middle cerebral artery and angioplasty was done to push the device into the A1 segment of the anterior cerebral artery, which was successfully achieved. Finally, in the third patient who had undergone coiling for a ruptured anterior communicating artery aneurysm 1.5 years prior, aneurysmal regrowth was detected on follow-up angiogram; after deployment, the device migrated distally to the ipsilateral A2 segment of the anterior cerebral artery, leaving the aneurysm neck uncovered. Hence, a second device was deployed proximally to cover the aneurysm neck adequately (Fig. 1). The mRS at 3 months was noted to be worse in the patient who had suffered the malignant middle cerebral artery infarct (Table 2).

\section{DISCUSSION}

In this study, we noted that a wide variety of aneurysms could be treated with flow diverter stenting, notably unruptured ones, but also aneurysms that grew after coiling/ clipping or recently ruptured ones that were deemed unsuitable for treatment options like coiling or clipping. The salient features and findings of the study are detailed below.

The study population showed a female predominance, as is noted in most previous DED studies. However, the mean age of the cohort was around 5-10 years older than that noted in most previous study populations. $6,8,12,17,18$ In the current study, we noted that most patients harbored single aneurysms, while 7 were noted to have multiple ones. Multiple aneurysms have been noted in several earlier trials and are of clinical concern, as some of patients harbouring these would need treatment for more than 1 of them. In the study conducted by Trivelato et al. ${ }^{6}, 151$ procedures were performed in over 146 patients harboring 183 intracranial aneurysms. Similarly, Daglioglu et al. ${ }^{12}$ noted 182 aneurysms in 146 individuals. Kallmes et al. ${ }^{19}$, Killer-Oberpfalzer et al. ${ }^{20}$, and Foa Torres et al. ${ }^{21}$ are other notable trials using other flow diverter devices where several patients harboring multiple aneurysms were identified. Other features pertaining to the 
distribution, morphology, and clinical characteristics in the current study are that most of the aneurysms were located in the anterior circulation, most of them commonly involved the internal carotid artery, most were unruptured, and most were saccular. Most earlier studies are in line with these findings. ${ }^{6,12}$ There was a large variation in aneurysm size noted in the current study, ranging from the very small $(1 \mathrm{~mm})$ to the very large $(35 \mathrm{~mm})$. Another notable feature was that a majority of the aneurysms were wide-necked. Small aneurysms and wide-necked ones, especially ruptured ones, are particularly difficult as they may not be amenable to coiling at all or may need adjunctive treatments. Flow diverter devices may be a feasible option in these cases. ${ }^{7,8,12,17,18,22,23}$ In the current study, adjunctive balloon angioplasty was employed in 5 (5.2\%) patients, while coiling of the aneurysmal sac was carried out in 12 (12.5\%). Angioplasty was employed in 1 patient with an anterior cerebral artery dissecting aneurysm in whom the device had landed on the terminal internal carotid artery causing flow-limitation in the middle cerebral artery, which was described above. In the rest of the 4 patients, angioplasty was done to attain perfect apposition of the stent to the vessel wall when a focal area of suboptimal device expansion was noted by the operator after complete deployment. Taschner et al. ${ }^{18}$ noted the use of adjunctive balloon angioplasty in 18 (19\%) of the procedures, while additional coiling was done in 47 (49\%). In their series, the mean aneurysm size was larger than in the current study. Trivelato et al. ${ }^{6}$ had noted additional use of balloon angioplasty in 31 (20.5\%) and coiling in 9 (6\%). As far as periprocedural complications were concerned, despite the varied morphology
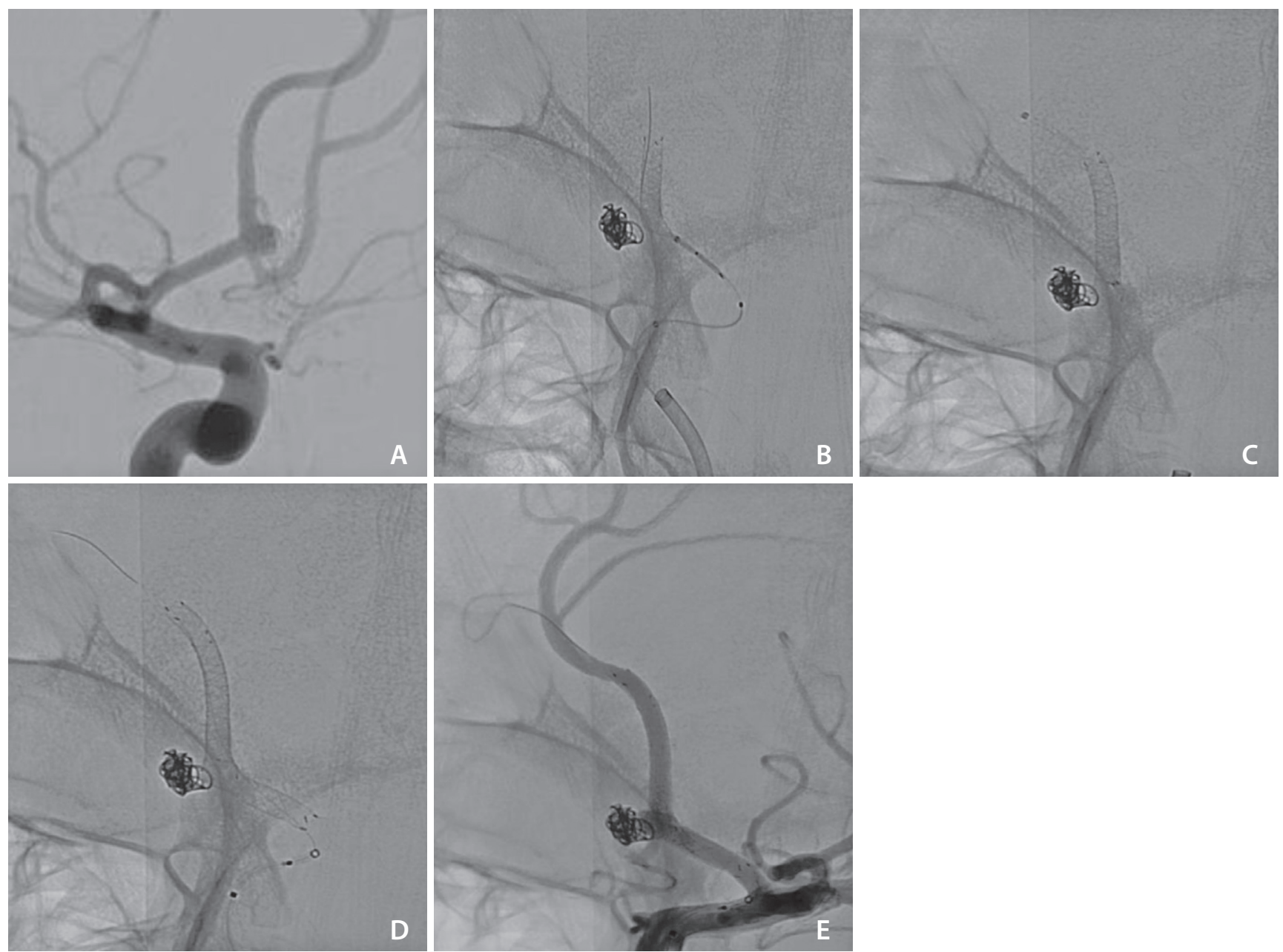

Fig. 1. A middle-aged individual who had undergone coiling of anterior communicating artery aneurysm (AComA) 6 months ago for subarachnoid haemorrhage, currently asymptomatic. (A) Regrowth of AComA aneurysm. (B) Derivo 2.5×20 device deployed through Neuroslider 21 microcatheter through 6F Benchmark guiding catheter. (C) Device migrated distally leaving the aneurysm neck unprotected. (D) Derivo 3.5×25 deployed in a telescopic fashion, covering the aneurysm neck. (E) Post-procedure angiogram showed normal distal vasculature and well covered aneurysm neck. 
and size of the aneurysms, the safety profile with the DED was noted to be very favorable. This is underlined by the fact that clinically significant periprocedural complications were noted in only 1 individual out of the 96 studied. Other DED studies have noted periprocedural complications of clinical concern ranging from around 3\% to just above 10\% (Table 3).

Fish-mouthing was noted in one case in the current study. This is in contrast to the study conducted by Taschner et al. ${ }^{18}$ who noted this problem to occur in $11.5 \%$ (11 of 96 ) of their cohort. However, Trivelato et al. ${ }^{6}$ noted this particular problem in 1.8\% (2 out of 151) procedures that they carried out, which, more or less, is similar to our findings. However, we note here that the study populations may not be comparable, as may be seen from the differences in the mean aneurysm sizes. In the current study, we noted thromboembolic complications in 1 individual. Periprocedural thromboembolism was noted in 5\% in the series published by Taschner et al. ${ }^{18}$, in $5.2 \%$ in the series by Daglioglu et al. ${ }^{12}$, and in $8.5 \%$ in the series published by Goertz et al. ${ }^{17}$ (Table 3). Pierot et al. ${ }^{24}$ in their study with the flow-redirection endoluminal device (FRED) embolic device noted periprocedural thromboembolic events in 4.8\% (5 out of 103) patients. In the study carried out by Berge et al. ${ }^{25}$, a periprocedural complication rate of $7.7 \%$ ( 5 out of 65 ) with the use of the Silk flow diverter device was noted. We did not notice any periprocedural hemorrhages, which was an uncommon event in the other Derivo series as well. ${ }^{6,8}, 12,17,18$ A recent meta-analysis of 8 studies with the Pipeline Flex flow diverter device showed a periprocedural risk of major complications of $1.8 \%$ and periprocedural risk of death of $0.8 \%$. However, here only unruptured aneurysms were studied. ${ }^{26}$ Despite that, the low complication rates might suggest an overall trend towards better safety profiles of second-generation devices. So also, a recent prospective trial has shown the safety and efficacy of these devices in small- and medium-sized aneurysms; and, thus, they are a good alternative to coiling for this category of unruptured aneurysms. ${ }^{27}$

As is depicted in Table 1, Pipeline Shield, FRED, and Surpass are US Food and Drug Administration approved while Derivo and Silk are not yet approved. Derivo and Pipeline Shield come with a surface coating and are claimed to be less thrombogenic compared to the other devices. FRED has an overlap stent design flow diverter and does not have a flow diversion effect at its ends. The newer generation of the Silk Vista Baby flow diverter is unique in the sense that it can be delivered in smaller vessels through a 0.17 -inch microcatheter. ${ }^{28}$ Thus the options for treatment of aneurysms have increased with the advent of new technology. However, without a head-to-head randomized controlled trial comparing different available devices, it is difficult to conclude the superiority of one device over the others. Newer generation devices seem preferable to the older generation ones given their ease of use, improved in vivo visibility, and lower profile. Nevertheless, it is important to note that, though there is an improvement in the safety profile of the newer devices, the risks with these devices are an important consideration and may lead to devastating consequences.

The most important limitation of this study is its lack of long-term follow-up data. The treatment of aneurysms with flow diverters cannot be deemed a success without demonstrating a complete and lasting cure, which mandates follow-up angiographic data over a period of several months if not years. Second, this was a retrospective single-arm study. A comparative study with prospective data collection and randomization to the use of other devices against the current device with appropriate blinding would have been an ideal scenario. Third, this was carried out at different centers by different interventionists who may show variations in skills

Table 3. Periprocedural intracranial adverse events of clinical concern (thromboembolism/hemorrhage) with Derivo Embolization Device in various studies

\begin{tabular}{lcccc}
\hline Study & Number of patients & Aneurysm size $(\mathrm{mm})$ & Adverse events & Ruptured \\
\hline Current study & 96 & $9.8 \pm 8.2$ & $1(1)$ & $18(18.7)$ \\
\hline Taschner et al. (2020) & 96 & $14.2 \pm 16.9$ & $5(5.2)$ & $15(15.6)$ \\
Daglioglu et al. (2020) & 146 & 8.3 & $8(5.5)$ & $46(31.5)$ \\
Trivelato et al. (2019) & 146 & $6.7 \pm 5.1$ & $5(3.4)$ & $6(4.1)$ \\
Goertz et al. (2019) & 59 & $8.1 \pm 6.2$ & $6(10.2)$ & $8(13.6)$ \\
Akgul et al. (2016) & 24 & $9.5 \pm 8.2$ & $3(12.5)$ & $1(4.2)$ \\
\hline
\end{tabular}

Values are presented as number (\%) or mean \pm standard deviation. 
and techniques.

Nevertheless, to the best of our knowledge, this is the first Indian multicenter study pertaining to the DED. Even though the study design was not perfect, still, a low periprocedural complication rate gives confidence about its procedural ease and safety regarding the future use of this newer generation flow diverter device. We may look upon this study as a foundation for larger studies in the future to validate the current findings and observe the angiographic cure rates with this device over longer periods of time.

\section{CONCLUSION}

The DED is a newer generation flow diverter stent with low peri-procedural complication rates. Though the construct of the device comes with a promise for better results, larger prospective studies with longer follow-ups, especially with a comparison with other available flow diverter devices may conclusively prove its efficacy and utility in the long run.

\section{Fund}

None.

\section{Ethics Statement}

This study was approved by the Institutional Review Board of Narayana Health City, Bangalore. The board waived the need for patient consent given the retrospective nature of the study. Since the consent for publication was not available for the patients mentioned in the figures, patient's information was anonymized by removing the sex and specific age.

\section{Conflicts of Interest}

The authors have no conflicts to disclose.

\section{Author Contributions}

Concept and design: VH and NPM. Analysis and interpretation: NPM, VH, and MM. Data collection: NPM, MM, AB, SP, ND, $M C, V G$, and VH. Writing the article: NPM, MM, and VH. Critical Revision: VH and NPM. Final approval of the article: NPM, $M M, A B, S P, N D, M C, V G$, and VH. Overall Responsibility: VH.

\section{ORCID}

Niranjan Prakash Mahajan: https://orcid.org/0000-0002-2432-4507 Mudasir Mushtaq: https://orcid.org/0000-0002-6752-594X

Amit Bhatti: https://orcid.org/0000-0001-6607-457X
Sukalyan Purkayastha: https://orcid.org/0000-0003-2515-3401

Nitin Dange: https://orcid.org/0000-0003-0356-2511

Mathew Cherian: https://orcid.org/0000-0001-6015-7278

Vipul Gupta: https://orcid.org/0000-0002-3355-0207

Vikram Huded: https://orcid.org/0000-0001-5018-8003

\section{REFERENCES}

1. Molyneux AJ, Kerr RS, Yu LM, Clarke M, Sneade M, Yarnold JA, et al.; International Subarachnoid Aneurysm Trial (ISAT) Collaborative Group. International subarachnoid aneurysm trial (ISAT) of neurosurgical clipping versus endovascular coiling in 2143 patients with ruptured intracranial aneurysms: a randomised comparison of effects on survival, dependency, seizures, rebleeding, subgroups, and aneurysm occlusion. Lancet 2005;366:809-817

2. Piotin M, Spelle L, Mounayer C, Salles-Rezende MT, Giansante-Abud D, Vanzin-Santos $R$, et al. Intracranial aneurysms: treatment with bare platinum coils--aneurysm packing, complex coils, and angiographic recurrence. Radiology 2007;243:500-508

3. Lylyk P, Miranda C, Ceratto R, Ferrario A, Scrivano E, Luna HR, et al. Curative endovascular reconstruction of cerebral aneurysms with the pipeline embolization device: the Buenos Aires experience. Neurosurgery 2009;64:632-642; discussion 642-643; quiz N6

4. Nelson PK, Lylyk P, Szikora I, Wetzel SG, Wanke I, Fiorella D. The pipeline embolization device for the intracranial treatment of aneurysms trial. AJNR Am J Neuroradio/ 2011;32:34-40

5. Becske T, Kallmes DF, Saatci I, McDougall CG, Szikora I, Lanzino G, et al. Pipeline for uncoilable or failed aneurysms: results from a multicenter clinical trial. Radiology 2013;267:858-868

6. Trivelato FP, Abud DG, Ulhôa AC, Waihrich ES, Abud TG, Castro Afonso LH, et al. Derivo embolization device for the treatment of intracranial aneurysms. Stroke 2019;50:2351-2358

7. Campos JK, Lien BV, Wang AS, Lin LM. Advances in endovascular aneurysm management: coiling and adjunctive devices. Stroke Vasc Neurol 2020;5:14-21

8. Akgul E, Onan HB, Akpinar S, Balli HT, Aksungur EH. The DERIVO embolization device in the treatment of intracranial aneurysms: short- and midterm results. World Neurosurg 2016;95:229-240

9. Wakhloo AK, Gounis MJ. Revolution in aneurysm treatment: flow diversion to cure aneurysms: a paradigm shift. Neurosurgery 2014;61 Suppl 1:111-120

10. Chiu AH, Cheung AK, Wenderoth JD, De Villiers L, Rice H, Phatouros CC, et al. Long-term follow-up results following elective 
treatment of unruptured intracranial aneurysms with the pipeline embolization device. AJNR Am J Neuroradiol 2015;36:17281734

11. Kallmes DF, Hanel R, Lopes D, Boccardi E, Bonafé A, Cekirge S, et al. International retrospective study of the pipeline embolization device: a multicenter aneurysm treatment study. AJNR Am J Neuroradio/ 2015;36:108-115

12. Daglioglu E, Akmangit I, Acik V, Alagoz F, Sayin B, Uckun OM, et al. The experience of the Derivo $\hat{A}^{\oplus}$ embolisation device in intracranial aneurysms. Turk Neurosurg 2020;30:30-37

13. Patel A, Miller TR, Shivashankar R, Jindal G, Gandhi D. Early angiographic signs of acute thrombus formation following cerebral aneurysm treatment with the Pipeline embolization device. J Neurointerv Surg 2017;9:1125-1130

14. Brinjikji W, Murad MH, Lanzino G, Cloft HJ, Kallmes DF. Endovascular treatment of intracranial aneurysms with flow diverters: a meta-analysis. Stroke 2013;44:442-447

15. Walcott BP, Stapleton CJ, Choudhri O, Patel AB. Flow diversion for the treatment of intracranial aneurysms. JAMA Neurol 2016;73:1002-1008

16. Ley D, Mühl-Benninghaus R, Yilmaz U, Körner $H$, Cattaneo GFM, Mailänder W, et al. The derivo embolization device, a second-generation flow diverter for the treatment of intracranial aneurysms, evaluated in an elastase-induced aneurysm model. Clin Neuroradio/ 2017;27:335-343

17. Goertz L, Dorn F, Kraus B, Borggrefe J, Forbrig R, Schlamann M, et al. Improved occlusion rate of intracranial aneurysms treated with the derivo embolization device: one-year clinical and angiographic follow-up in a multicenter study. World Neurosurg 2019;126:e1503-e1509

18. Taschner CA, Stracke CP, Dorn F, Kadziolka KB, Kreiser K, Solymosi $L$, et al. Derivo embolization device in the treatment of unruptured intracranial aneurysms: a prospective multicenter study. J Neurointerv Surg 2021;13:541-546

19. Kallmes DF, Brinjikji W, Cekirge S, Fiorella D, Hanel RA, Jabbour $P$, et al. Safety and efficacy of the Pipeline embolization device for treatment of intracranial aneurysms: a pooled analysis of 3 large studies. J Neurosurg 2017;127:775-780

20. Killer-Oberpfalzer M, Kocer N, Griessenauer CJ, Janssen H, Engelhorn T, Holtmannspötter M, et al. European multicenter study for the evaluation of a dual-layer flow-diverting stent for treatment of wide-neck intracranial aneurysms: the European flow-redirection intraluminal device study. AJNR Am J Neuroradio/ 2018;39:841-847

21. Foa Torres G, Roca F, Noguera A, Godes J, Petrocelli S, Aznar I, et al. Silk flow-diverter stent for the treatment of complex intracranial aneurysms: a one-year follow-up multicenter study. Interv Neuroradiol 2018;24:357-362

22. Chalouhi N, Zanaty M, Whiting A, Yang S, Tjoumakaris S, Hasan $D$, et al. Safety and efficacy of the Pipeline embolization device in 100 small intracranial aneurysms. J Neurosurg 2015;122:14981502

23. Meyers PM, Coon AL, Kan PT, Wakhloo AK, Hanel RA. SCENT trial. Stroke 2019;50:1473-1479

24. Pierot L, Spelle L, Berge J, Januel AC, Herbreteau D, Aggour M, et al. SAFE study (Safety and efficacy Analysis of FRED Embolic device in aneurysm treatment): 1-year clinical and anatomical results. J Neurointerv Surg 2019;11:184-189

25. Berge J, Biondi A, Machi P, Brunel H, Pierot L, Gabrillargues J, et al. Flow-diverter silk stent for the treatment of intracranial aneurysms: 1-year follow-up in a multicenter study. AJNR Am J Neuroradiol 2012;33:1150-1155

26. Bhatia KD, Kortman H, Orru E, Klostranec JM, Pereira VM, Krings T. Periprocedural complications of second-generation flow diverter treatment using Pipeline Flex for unruptured intracranial aneurysms: a systematic review and meta-analysis. J Neurointerv Surg 2019;11:817-824

27. Hanel RA, Kallmes DF, Lopes DK, Nelson PK, Siddiqui A, Jabbour $\mathrm{P}$, et al. Prospective study on embolization of intracranial aneurysms with the pipeline device: the PREMIER study 1 year results. J Neurointerv Surg 2020;12:62-66

28. Bhogal P, Wong K, Uff C, Wadley J, Makalanda HL. The Silk Vista Baby: initial experience and report of two cases. Interv Neuroradiol 2019;25:530-538 